ICONE19-43111

\title{
Engineering Design of IFMIF/EVEDA Lithium Test Loop: Electro-Magnetic Pump and Pressure Drop
}

\author{
H. Kondo \\ Japan Atomic Energy \\ Agency, 311-1393, O-arai, \\ Ibaraki, Japan \\ Phone:+8-29-267-4141 \\ Email Address: \\ kondo.hiroo@jaea.go.jp \\ H. Iuchi \\ Japan Atomic Energy \\ Agency, 311-1393, O-arai, \\ Ibaraki, Japan \\ T. Kanemura \\ Japan Atomic Energy \\ Agency, 311-1393, O-arai, \\ Ibaraki, Japan \\ I. Mastushita \\ Mitsubishi Heavy Industries \\ Mechatronics Systems, Ltd., \\ 652-0863, Kobe, Hyogo, \\ Japan
}

\author{
T.Furukawa \\ Japan Atomic Energy \\ Agency, 311-1393, O-arai, \\ Ibaraki, Japan
}

M. Ida

Japan Atomic Energy

Agency, 319-1195, Tokai, Ibaraki, Japan

H. Horiike

Osaka University 565-0871, Suita, Osaka, Japan

$$
\begin{gathered}
\text { E. Wakai } \\
\text { Japan Atomic Energy } \\
\text { Agency, 319-1195, Tokai, } \\
\text { Ibaraki, Japan }
\end{gathered}
$$

\author{
Y. Hirakawa \\ Japan Atomic Energy \\ Agency, 311-1393, O-arai, \\ Ibaraki, Japan
}

Keywords: ITER-BA, IFMIF/EVEDA, Li target, liquid metal loop, electro-magnetic pump, cavitation

\begin{abstract}
The Engineering Validation and Engineering Design Activities (EVEDA) for the International Fusion Materials Irradiation Facility (IFMIF) is proceeding as one of the ITER Broader Approach (ITER-BA). A Li circulation loop for testing hydraulic stability of the $\mathrm{Li}$ target (high speed free-surface flow of liquid $\mathrm{Li}$ as a beam target) and $\mathrm{Li}$ purification traps are under construction in the Japan Atomic Energy Agency as a major Japanese activities in the EVEDA. This paper presents specification of an electro-magnetic pump (EMP) for the EVEDA Li Test Loop (ELTL) and evaluation of the pressure drop in the main loop of the ELTL. The EMP circulates the liquid $\mathrm{Li}$ at a large flow rate up to $0.05 \mathrm{~m}^{3} / \mathrm{s}$ (3000 l/min) under a vacuum cover gas (Ar) pressure of $10^{-3} \mathrm{~Pa}$, thus the evaluation of cavitation generation is a crucial issue. The EMP used in the ELTL consists of two EMPs aligned in series through a U-tube whose size of one EMP is $0.8 \mathrm{~m}$ square and $2.6 \mathrm{~m}$ in length. The calculation of the pressure drop in the main Li loop to the EMP is approx. $25 \mathrm{kPa}$ at the design maximum flow rate of $0.05 \mathrm{~m}^{3} / \mathrm{s}$. On the other hand the height from the EMP to a $\mathrm{Li}$ tank to supply $\mathrm{Li}$ to the EMP is designed to be $9.72 \mathrm{~m}$, and
\end{abstract}

secures a static pressure and the cavitation number of $18 \mathrm{kPa}$ and 3.4 respectively at the maximum flow rate in a vacuum condition. As a result, it is confirmed to prevent cavitation at the inlet of the EMP in this design.

\section{INTRODUCTION}

The International Fusion Materials Irradiation Facility (IFMIF) is aimed at producing an intense high energy neutron flux generated by a deuteron $\left(\mathrm{D}^{+}\right)$- lithium $(\mathrm{Li})$ nuclear reaction. In the current concept of the IFMIF, two 40 $\mathrm{MeV}$-deuteron beams whose total current is $250 \mathrm{~mA}$ are injected into a liquid Li stream flowing at a speed of $15 \mathrm{~m} / \mathrm{s}$. The $\mathrm{Li}$ stream, hereinafter called the $\mathrm{Li}$ target, is a free-surface flow produced by a double contraction nozzle and flows through a concave flow channel in a vacuum of $10^{-3} \mathrm{~Pa}$.

At present, Engineering Validation and Engineering Design Activities called EVEDA (Garin,P., 2008, Garin,P., 2009) for the IFMIF is carried out under an international collaboration known as the ITER Broader Approach (BA) (Matsuda,S., 2007, Tsunematsu, T., 2009) between Japan and the EU. The EVEDA tasks related to the Li target facility 
consist of six tasks which are (I) construction and operation of a Li test loop; (II) diagnostics for the Li target; (III) erosion/corrosion for loop structure materials; (IV) a $\mathrm{Li}$ purification system; (V) remote handling; (VI) IFMIF engineering design (Nakamura,H.,et al., 2009). Among these tasks, as a major Japanese activity, the EVEDA Li Test Loop (ELTL) is now under construction at the O-arai site of the Japan Atomic Energy Agency (JAEA). It is scheduled for completion at the end of Feb. 2011 and for operation for 2 years from May, 2011.

The ELTL was designed to have the major components necessary to produce the Li target envisaged in the actual IFMIF, although the width of the Li target in the ELTL has been reduced to $1 / 2.6$ of that of the IFMIF because of cost reduction. The ELTL features that it is able to produce the $\mathrm{Li}$ target at the high flow velocity of $20 \mathrm{~m} / \mathrm{s}$ in a vacuum condition of $10^{-3} \mathrm{~Pa}$ along the concave back plate and that it equips a complete set of purification traps and monitors. Major issues to be investigated and validated in the ELTL are the hydraulic stability of the Li target; the Li purification system consisting of three impurity traps. Based on outcomes from these validation tests, the current specifications of the target, traps and monitors are expected to be validated or re-evaluated based on the outcomes for the goal of designing the Li target and the purification system for the actual IFMIF.

This paper focuses on the design of the ELTL concerning to an electro-magnetic pump (EMP) for Li circulation. The ELTL is designed to use an EMP whose flow rate is up to $0.05 \mathrm{~m}^{3} / \mathrm{s}$ (3000 L $/ \mathrm{min}$ ) to achieve the Li target at a velocity of $20 \mathrm{~m} / \mathrm{s}$ in the target assembly where the Li target produced by a nozzle.

In addition to this large flow rate, the Li target is produced in a vacuum condition of $10^{-3} \mathrm{~Pa}$ and collected into a quench tank which supplies Li to the EMP whose cover gas pressure is also $10^{-3} \mathrm{~Pa}$. For these reasons, generation of cavitation at the EMP is a major design issue. This paper presents the design of the EMP used in the main $\mathrm{Li}$ loop after the description of the whole ELTL configuration. Then pressure drop in the main Li loop was calculated and generation of cavitation is discussed in this paper.

\section{EVEDA LI TEST LOOP OVER VIEW}

Fig.1 shows the piping and instrumentation diagram (P\&ID) of the ELTL (Kondo,H., et al., 2009). The ELTL consists of two major Li loops which are the main loop and the purification loop with the impurity monitoring loop. The main Li loop was designed to supply liquid $\mathrm{Li}$ at controlled flow rate and temperature to the target assembly.

The main loop consists of 6-inch $\mathrm{Li}$ circulation pipes (partly 8-inch); the target assembly; the quench tank; the electro-magnetic pump (EMP); an electro-magnetic flow meter (EMF); a cooler; a surge tank; a dump tank. $\mathrm{Li}$ is circulated in the Li circulation pipe by the EMP and flows into the target assembly. The Li target is formed by a contraction nozzle at the target assembly and flows a concave flow channel in a vacuum of $10^{-3} \mathrm{~Pa}$. The $\mathrm{Li}$ after flowing the concave channel is collected into the quench tank, then flows down to the EMP to circulate in the Li pipe again.

The major design specifications of the ELTL, whose Li inventory is $5.0 \mathrm{~m}^{3}$ and platform size is roughly $20 \times 20 \times 20$ $\mathrm{m}$, are as follows: The design temperature is $400{ }^{\circ} \mathrm{C}$ and the steady-state operation ranges from 250 through $350{ }^{\circ} \mathrm{C}$; the design pressure ranges from a gauge pressure of $-0.1 \mathrm{MPa}$ through $0.75 \mathrm{MPa}$; the maximum flow rate of the main circulation pump is $0.05 \mathrm{~m}^{3} / \mathrm{s}$ (this flow rate corresponds to $20 \mathrm{~m} / \mathrm{s}$ at the target section. The piping and main construction consist of stainless steel (S.S.) type 304.

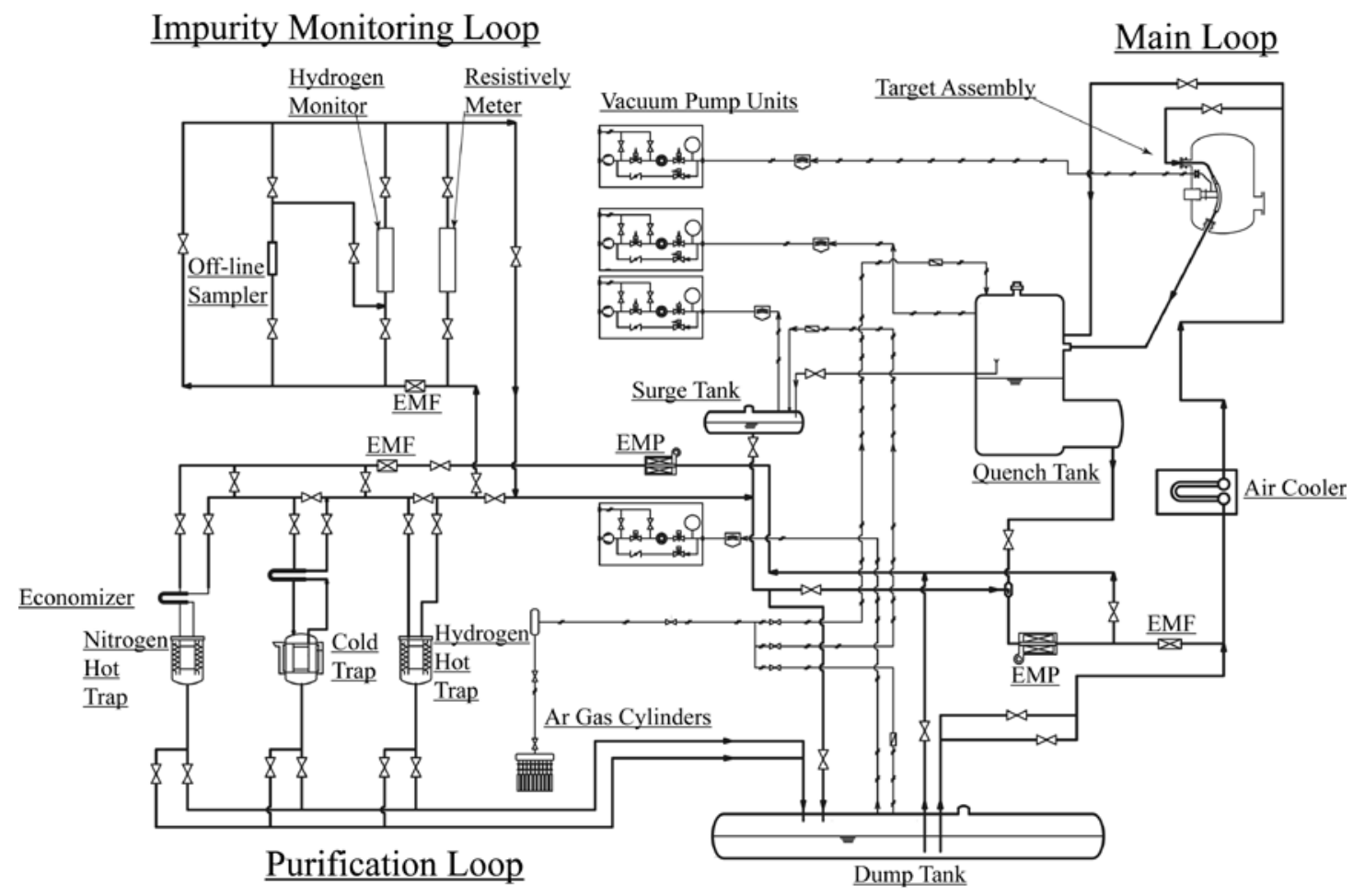

Fig. 1 P\&ID of the ELTL 


\section{DESIGN OF ELECTRO-MAGNETIC PUMP AND ELECTRO-MAGNETIC FLOW METER \\ 3.1. Design Specifications}

The main EMP circulates the liquid Li whose temperature range is 250 to $300{ }^{\circ} \mathrm{C}$ at flow rate up to $0.05 \mathrm{~m}^{3} / \mathrm{s}$. The major specification of the EMP is summarized in Table 1.

The EMP accompanies a permanent magnet type of Electro-magnetic flow meter (EMF) installed in the main $\mathrm{Li}$ loop for measurement of flow rate. In feedback control system of the ELTL, the signal of flow rate acquired from the EMF are used to control voltage of the EMP. The EMP and the EMF are equipped with heaters and thermocouples for preheating.

The structures of the EMP and EMF are described in the following sub-section. And also the envisaged discharge pressure of the EMP, the envisaged output voltage of EMF, and pressure drop is presented in the following section.
Table 1. EMP design specifications

\begin{tabular}{|l|l|}
\hline \multicolumn{1}{|c|}{ Item } & \multicolumn{1}{c|}{ Value } \\
\hline Pressure & -0.1 to $0.75 \mathrm{MPa}$ (gauge) \\
\hline Operation Temperature & $250-350^{\circ} \mathrm{C}$ \\
\hline Type & Annular linear induction \\
\hline Maximum flow rate & $0.05 \mathrm{~m}^{3} / \mathrm{s}(3,000 \mathrm{~L} / \mathrm{min})$ \\
\hline Fluid & Liquid lithium \\
\hline Material (Pipe) & S.S. 304 \\
\hline
\end{tabular}

\subsection{Structure}

Fig. 2 and Fig.3 depict the structures of the EMP and the EMF respectively. The EMP used in the ELTL consists of two EMPs aligned in series through a U-tube as shown in Fig.2. Size of one EMP is $0.8 \mathrm{~m}$ square and $2.6 \mathrm{~m}$ in length. Electric power of $350 \mathrm{kVA}$ is supplied for the whole EMP. The EMP is equipped with an air cooler for cooling coils, condenser, heaters and thermo-couples.
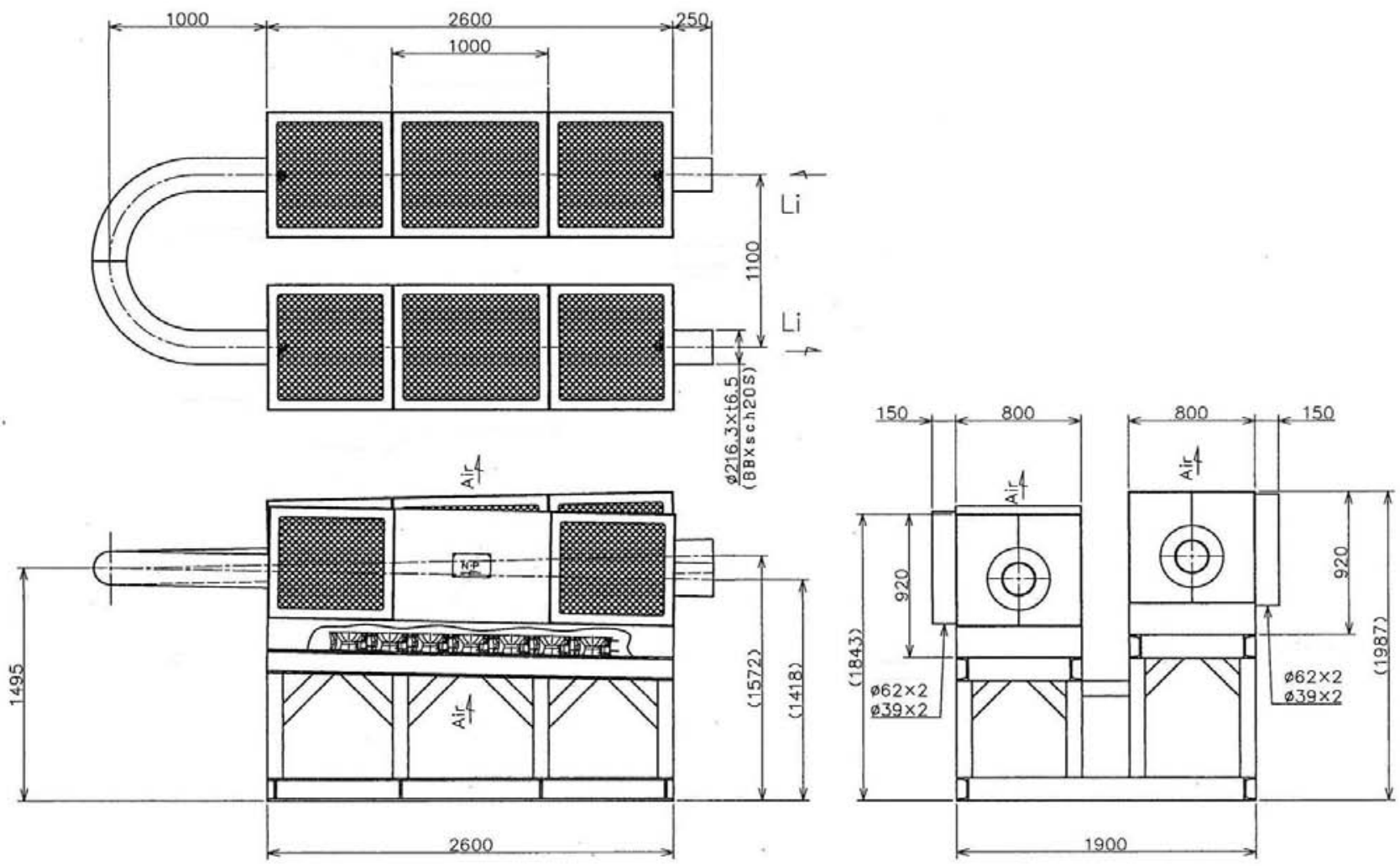

Fig.2 EMP Structure
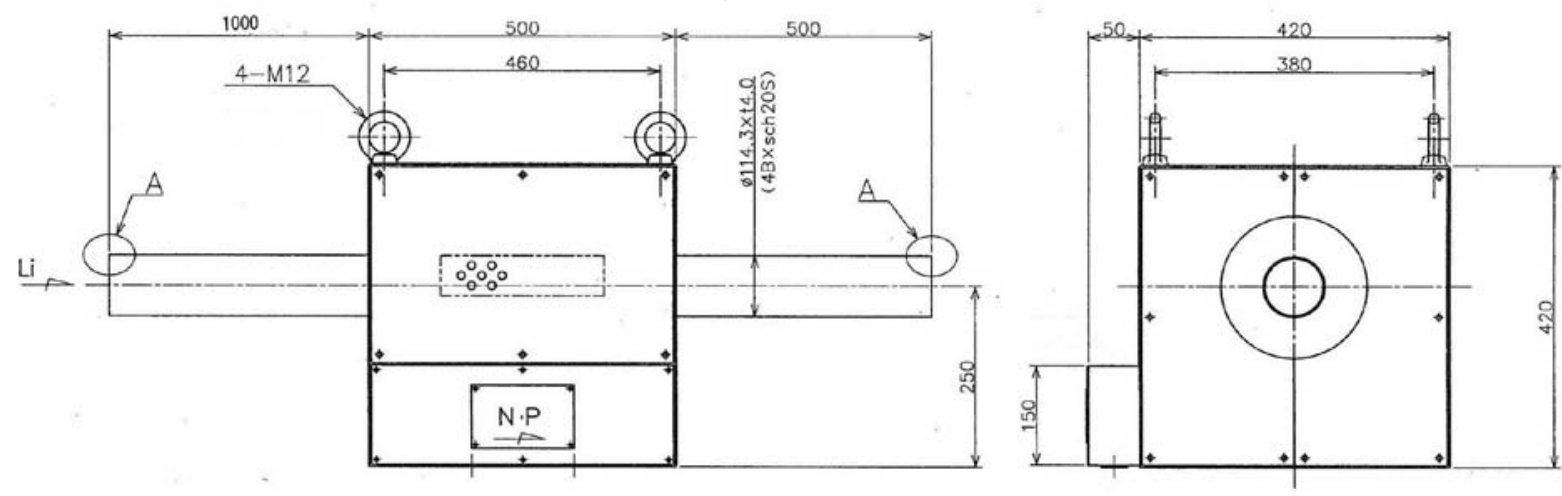

Fig.3 EMF Structure 
Diameter of the Li pipe of the EMP and EMF is 8-inch and 4-inch respectively. Since the Li pipe of the main loop is used 6-inch pipe, expansion and contraction pipes are installed at the upstream and the downstream of the EMP and the EMF respectively.

The EMP is placed and fixed on a mount as shown in Fig.2, on the other hand the EMF is suspended from the ceiling of the loop mount. The EMP is cooled by an air blower to remove heat generated at the coils. Air flows from bottom of the mount of the EMP as shown in Fig.2.

\subsection{Discharge pressure of EMP}

The envisaged discharge pressure of the EMP is shown in Fig.4 against flow rate. The maximum discharge pressure at the designed maximum flow rate of the loop, $0.05 \mathrm{~m}^{3} / \mathrm{s}$ (3000 $\mathrm{L} / \mathrm{min}$ ), is approximately 0.30 MPa.

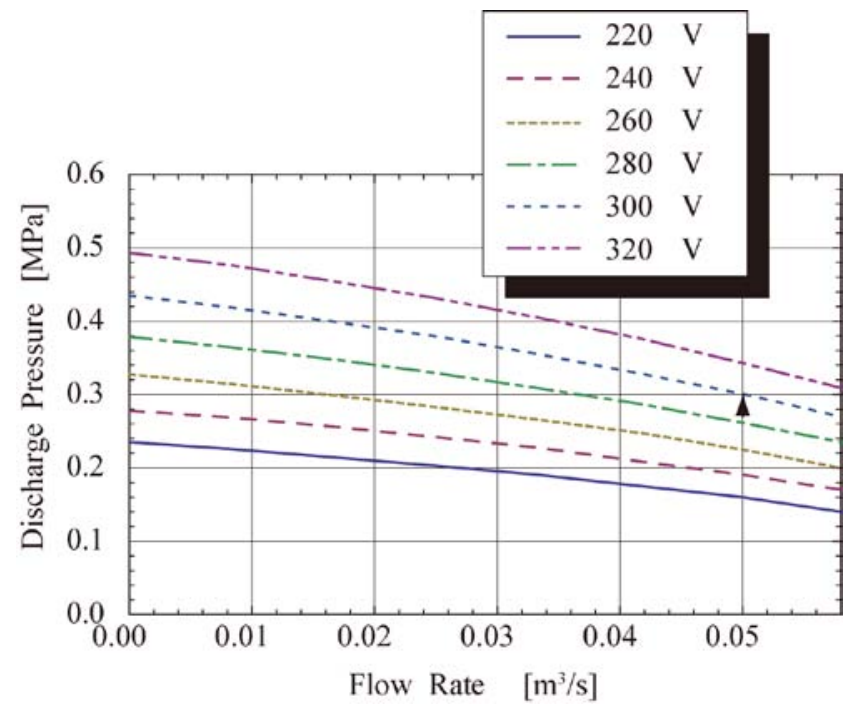

Fig. 4 Envisaged Output flow rate and pressure of EMP

\section{PRESSURE DROP CALCULATION OF THE MAIN LI LOOP}

\subsection{Calculation conditions for the piping}

In this section, the pressure drop in the main Li loop is calculated, and the static pressure of Li flow at the EMP is evaluated. The piping route for the $\mathrm{Li}$ main loop is schematically illustrated in Fig.5. Pressure drop calculated here is from the quench tank outlet to the EMP inlet.

The pressure drop is calculated based on the following conditions and is summarized in Table 2:

1. The main $\mathrm{Li}$ pipes consist of 6-inch drawn pipes made of S.S. 304 (partly 8-inch pipe) and contain 8 bends.

2. The curvature radius of the bends is $660 \mathrm{~mm}(\approx 4 \mathrm{~d})$.

3. The $\mathrm{Cv}$ value of a $\mathrm{Li}$ valve in this route is 408 provided by a manufacturer.

Table 2. Piping configuration

\begin{tabular}{|l|l|}
\hline Inside Diameter (d) [m] & 0.1552 \\
\hline Cross-sectional area $\left[\mathrm{m}^{2}\right]$ & 0.0189 \\
\hline Length of straight pipe (L) [m] & 25 \\
\hline Relative roughness ( $(\varepsilon / \mathrm{d})[-]$ & $9.8 \times 10^{-5}$ \\
\hline Number of bends (90 degree) [-] & 8 \\
\hline
\end{tabular}

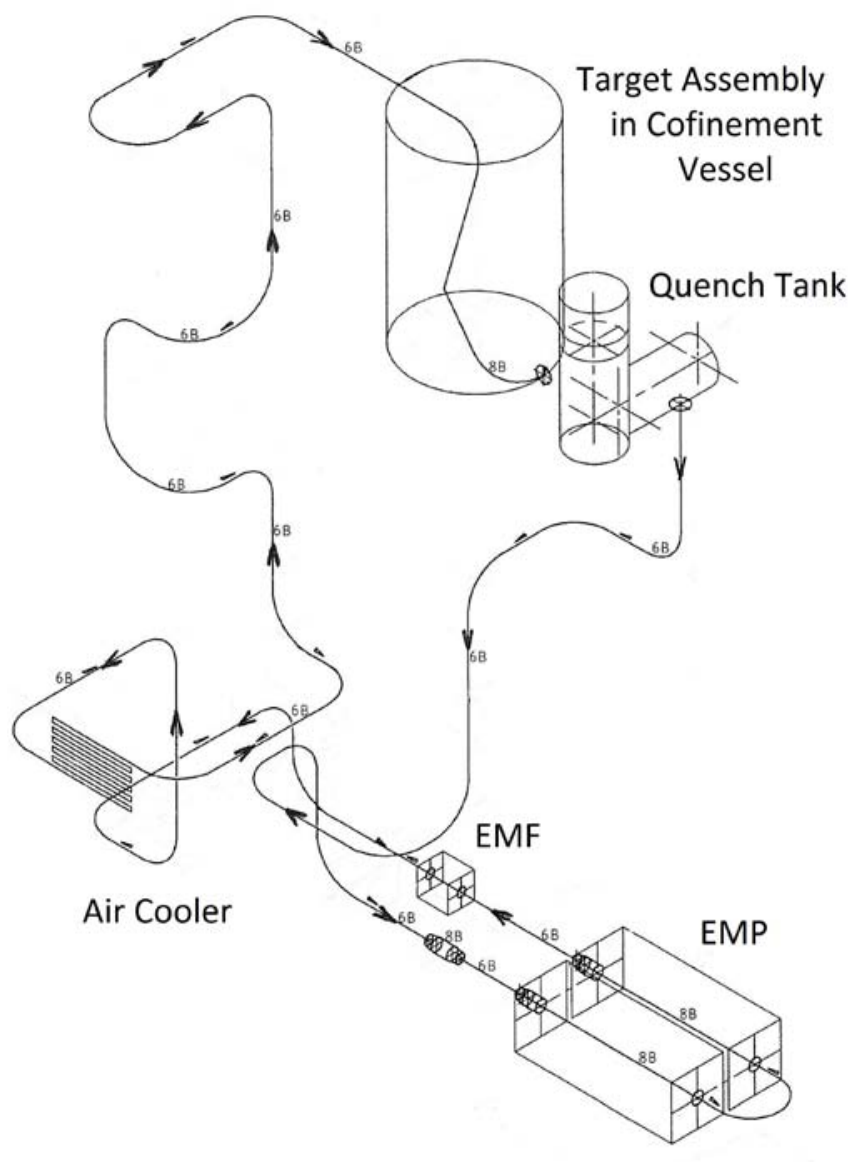

Fig.5 Main loop piping route

\subsection{Calculation method}

Physical properties of $\mathrm{Li}$ used in this calculation are listed in Table 3 at the temperatures of 250,300 and $350{ }^{\circ} \mathrm{C}$. Density $\rho$, viscosity $\eta$, and vapor pressure $P v$ are expressed by the following empirical equations (Hua, T., 1995):

$$
\rho=515-0.101(t-200),(\text { Gol'tsova, E.I., 1966) }
$$

$$
\log \eta=-1.5064-0.737 \log T+\frac{109.9}{T},
$$

$$
\text { (Shpil'rain, E.E., 1965) }
$$

$$
\begin{aligned}
\log P_{v}= & 19.218-\frac{8551.2}{T}-3.80 \log T+6.72 \times 10^{-3} T^{3} \\
& -6.4 \times 10^{-6} T^{2}+2.687 \times 10^{-9} T^{3},
\end{aligned}
$$

(Nesmeyanov, An.N., 1961)

where $t$ and $T$ are temperature in degree $\left({ }^{\circ} \mathrm{C}\right)$ and in Kelvin (K) respectively. Kinematic viscosity $v$ is written as $v=\rho / \eta$.

Table 3 also shows the flow conditions such as the maximum flow rate; the mean flow velocities in the pipe and in an annular duct of the EMP at the maximum flow rate; Reynolds number. 
Table 3. Li Physical Properties and Flow Conditions

\begin{tabular}{|l|l|l|l|}
\hline Temperature $\left[{ }^{\circ} \mathrm{C}\right]$ & 250 & 300 & 350 \\
\hline Density $(\rho)\left[\mathrm{kg} / \mathrm{cm}^{3}\right]$ & 510 & 505 & 500 \\
\hline $\begin{array}{l}\text { Kinematic Viscosity }(\mathrm{v}) \\
{\left[\mathrm{m}^{2} / \mathrm{s}\right]}\end{array}$ & $0.983 \times 10^{-6}$ & $0.890 \times 10^{-6}$ & $0.816 \times 10^{-6}$ \\
\hline Vapor pressure [Pa] & $4.85 \times 10^{-6}$ & $1.12 \times 10^{-4}$ & $1.68 \times 10^{-3}$ \\
\hline Flow Rate (Max.) $\left[\mathrm{m}^{3} / \mathrm{s}\right]$ & 0.05 & 0.05 & 0.05 \\
\hline $\begin{array}{l}\text { Flow velocity in 6-inch } \\
\text { pipe(Max. ) [m/s] }\end{array}$ & 2.65 & 2.65 & 2.65 \\
\hline $\begin{array}{l}\text { Flow velocity in annular } \\
\text { duct of EMP (Max. ) }[\mathrm{m} / \mathrm{s}\end{array}$ & 4.54 & 4.54 & 4.54 \\
\hline $\begin{array}{l}\text { Reynolds number in } \\
\text { 6-inch pipe (Max. ) }\end{array}$ & $4.18 \times 10^{5}$ & $4.62 \times 10^{5}$ & $5.04 \times 10^{5}$ \\
\hline
\end{tabular}

Pressure drop in the straight pipe, $\Delta p_{s}$, was calculated using the Darcy-Weisbach formula as follow (Moody, L. F., 1944):

$$
\Delta p_{s}=f \cdot \frac{L}{D} \cdot \frac{\rho v^{2}}{2},
$$

where $f$ is a friction factor; $L$ and $D$ are the length and diameter of the pipe; $\rho$ is the density of the fluid; $V$ is the mean velocity of the fluid. The friction factor was obtained from the Moody chart (Moody, L. F., 1944).

Pipe elements in the present suction line are a pipe entrance from the quench tank, 8 bends and the inlet to the EMP. The pressure losses in these pipe elements were calculated by the following equation.

$$
\Delta p_{e}=\zeta \cdot \frac{\rho v^{2}}{2}
$$

where $\zeta$ is loss coefficient.

The curvature radius $R$ of a bend in this route is $660 \mathrm{~mm}$ and then the ratio of the curvature radius and the inside diameter of the pipe, $d$, is approximately 4 . At the inlet of the pump, the pipe is expanded to 8 inches from 6 inches, then the pipe become an annular channel. The inlet of the EMP is assumed as a combination of an expansion and a contraction pipe for this pressure drop calculation. The loss coefficients for the pipe entrance, the bends, the expansion and contraction are $0.5,0.16,1.0$ and 0.5 respectively.

As for the pressure drop in the valve, the $\mathrm{Cv}$ value is defined as the volume flow in gallons per minute of water at a temperature of $60^{\circ} \mathrm{F}$ with a pressure drop across the valve of 1 psi and written as follows:

$$
C_{v}=Q \cdot \sqrt{\frac{G}{\Delta P}} .
$$

Pressure drop in a valve was calculated by the above equation with a $\mathrm{Cv}$ value provided by a valve manufacturer. The $\mathrm{Cv}$ value of the valve in this route is 408 .

\subsection{Result and discussion}

The pressure drop at a flow rate of $0.05 \mathrm{~m}^{3} / \mathrm{s}$ at the temperatures of 250,300 and $350{ }^{\circ} \mathrm{C}$ are summarized in Table 4. This flow rate corresponds to $20 \mathrm{~m} / \mathrm{s}$ of a mean flow velocity of the Li target at the target assembly, and to the design maximum flow rate. As shown in the Table 4, the pressure drop at the valve account for approximately a half of the total in this piping route. Change of temperature in this range has no notable influence on the pressure drop.

Table 4. pressure drop at a flow rate of $0.05 \mathrm{~m}^{3} / \mathrm{s}$

\begin{tabular}{|l|l|l|l|}
\hline & $250\left[{ }^{\circ} \mathrm{C}\right]$ & $300\left[{ }^{\circ} \mathrm{C}\right]$ & $350\left[{ }^{\circ} \mathrm{C}\right]$ \\
\hline Quench tank outlet [kPa] & 0.896 & 0.887 & 0.878 \\
\hline Straight pipe [kPa] & 4.35 & 4.22 & 4.18 \\
\hline Bends [kPa] & 2.30 & 2.24 & 2.19 \\
\hline Valve [kPa] & 13.3 & 13.1 & 13.1 \\
\hline Pump inlet [kPa] & 4.42 & 4.37 & 4.33 \\
\hline Total [kPa] & 25.3 & 24.9 & 24.6 \\
\hline
\end{tabular}

Possibility of generation of cavitation at the inlet of the EMP was discussed as follows. The Bernoulli's equation in the form of pressure can be written as:

$$
\frac{1}{2} \rho v^{2}+\rho g h+p=\text { constant }
$$

where $\rho$ is the density of the fluid; $v$ the fluid velocity; $g$ the gravity acceleration; $h$ the elevation (height) from the reference point; $p$ the static pressure of the fluid.

In the present application, the static pressure at the annular channel of the EMP is obtained from by comparing the left part of the Bernoulli's equation at the quench tank and at the EMP with the pressure drop into consideration. The static pressure of the Li flow at the annular channel of the EMP is written as:

$$
p_{s}=p_{c g}+\rho g h-\frac{1}{2} \rho v_{a}^{2}-\Delta p,
$$

where $p_{s}$ is the static pressure of the Li flow at the annular channel; $p_{c g}$ the static pressure in the quench tank (i.e. Ar gas pressure used as cover gas); $h$ the height of Li level in the quench tank from the inlet of the EMP; $v_{a}$ the mean Li flow velocity at the annular channel; $\Delta p$ the pressure drop from the quench tank to the annular channel.

The static pressures at the annular channel at the maximum flow rate of $0.05 \mathrm{~m}^{3} / \mathrm{s}$ at the temperatures of 250, 300 and $350{ }^{\circ} \mathrm{C}$ are shown in Table 5 . In Table 5 , the static pressure at the quench tank, the first term of the Bernoulli's equation (the dynamic pressure) as well as the second term, and the pressure drop are also shown in this table. In these case, the static pressure at the quench tank is taken as $10^{-3} \mathrm{~Pa}$ which is envisaged in the actual IFMIF and the target vacuum level for the ELTL, and the height $h$ is designed to be $9.72 \mathrm{~m}$.

As shown in Table 5, the pressure by the elevation $(\rho g h)$ is around $48 \mathrm{kPa}$ in this temperature range and is roughly 2 times larger than the pressure drop which is 24.6 to $25.3 \mathrm{kPa}$. As a result, the static pressure of $\mathrm{Li}$ is estimated as the range of 17.9 to $18.1 \mathrm{kPa}$ and is confirmed far exceeding the vapor pressure of $\mathrm{Li}$, which is the range of $10^{-3}$ to $10^{-6} \mathrm{~Pa}$ as shown in Table 3. 
Table 5. Static pressure at the annular duct and Cavitation number

\begin{tabular}{|l|l|l|l|}
\hline & $250\left[{ }^{\circ} \mathrm{C}\right]$ & $300\left[{ }^{\circ} \mathrm{C}\right]$ & $350\left[{ }^{\circ} \mathrm{C}\right]$ \\
\hline $\begin{array}{l}\text { Static pressure }[\mathrm{Pa}] \\
\text { (at the quench tank) }\end{array}$ & $10^{-3}$ & $10^{-3}$ & $10^{-3}$ \\
\hline$\rho$ gh [kPa] & 48.6 & 48.0 & 47.4 \\
\hline $\begin{array}{l}\text { Dynamic pressure [kPa] } \\
\text { at the annular duct) }\end{array}$ & 5.25 & 5.20 & 5.14 \\
\hline Pressure drop [kPa] & 25.3 & 24.9 & 24.6 \\
\hline $\begin{array}{l}\text { Static pressure [kPa] } \\
\text { at the annular duct }\end{array}$ & 18.1 & 18.0 & 17.9 \\
\hline Cavitation number $\sigma$ & 3.43 & 3.46 & 3.47 \\
\hline
\end{tabular}

As for evaluation for cavitation inception, the following cavitation number, $\sigma$, is used (Hammitt, F. G., 1980):

$$
\sigma=\frac{p_{s}-p_{v}}{p_{d}}
$$

where $p_{s}$ is the static pressure at the evaluation point; $p_{v}$ the vapor pressure of the fluid; $p_{d}\left(=\rho v^{2} / 2\right)$ the dynamic pressure of the flow at the evaluation point. The caviation number in the present cases are 3.43 to 3.47 as shown in Table 5 .

Cavitation number against Reynolds number in the present case is plotted in Fig.6. In Fig.6., the friction factor is obtained from the following Colebrook formula (Moody, L. F., 1944):

$$
\frac{1}{\sqrt{f}}=-2 \log \left(\frac{\varepsilon / D}{3.7}+\frac{2.51}{R e \sqrt{f}}\right),
$$

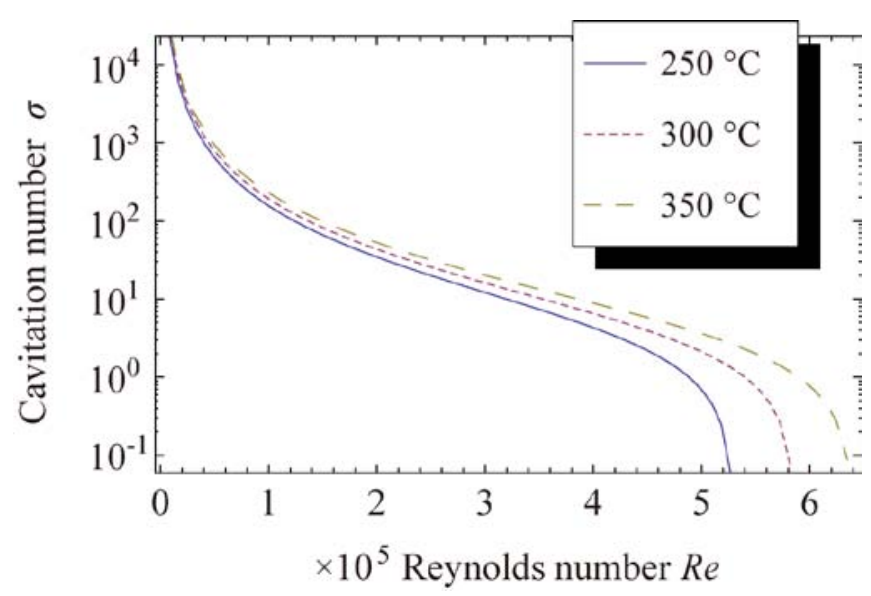

Fig.6. Cavitation number vs. Reynolds number

As shown in Table 5 and Fig.6, The Cavitation number $\sigma$ is around 3 at the design maximum flow rate of $0.05 \mathrm{~m}^{3} / \mathrm{s}(\mathrm{Re}=$ 4 to $5 \times 10^{5}$ ). The Cavitation number $\sigma$ at the inception varies depending on flow conditions, e.g. dissolved gas and pipe surface roughness.

In the present case, since the whole loop is maintained under a vacuum condition of $10^{-3} \mathrm{~Pa}$, the amount of dissolved gas is supposed to be small. In addition, the surface roughness of the pipe is also small because the $\mathrm{Li}$ piping employs drawn pipe $\left(\varepsilon / \mathrm{d}=9.8 \times 10^{-5}\right.$ according to Moody, L. F., 1944). As a similar study to the present case, the cavitation inception at an EMP in a Li loop under vacuum conditions was measured by an acceleration sensor and evaluated by using the same cavitation number by G. Dell'Orco (Dell'Orco, G.., 2004). In his report, the cavitation inception was observed when the Cavitation number reached to 0 (i.e.when the Li static pressure equals to its vapor pressure). In the present case, the Cavitation number exceeds 3 even in the severest condition of $0.05 \mathrm{~m}^{3} / \mathrm{s}$ and $10^{-3} \mathrm{~Pa}$. Besides, the static pressure is enormous compared to its vapor pressure. Thus, it can be concluded that the design of the height $h=$ $9.72 \mathrm{~m}$ in the ELTL main Li loop has sufficiently large to prevent the cavitation.

\section{SUMMARRY}

The EVEDA Li Test Loop (ELTL) is under construction as a major Japanese activities for the IFMIF/EVEDA in the ITER-BA. The ELTL was designed to produce the Li target which is a free-surface flow and flows at a velocity of $20 \mathrm{~m} / \mathrm{s}$ in a vacuum condition of $10^{-3} \mathrm{~Pa}$. To achieve this large flow rate under the vacuum condition, it is required to pay attention to the design of the EMP as well as the pressure drop. This paper presents the overview of the ELTL; the specification and the structure of the electro-magnetic pump (EMP) for Li circulation; the evaluation of the pressure drop and the cavitation number. The summary and conclusion of this paper are follows:

The main Li loop of the ELTL equips the EMP which circulates $\mathrm{Li}$ in 6-inch piping at the maximum flow rate of $0.05 \mathrm{~m}^{3} / \mathrm{s}$ under a vacuum cover gas condition of $10^{-3} \mathrm{~Pa}$. The EMP is annular liner induction pump type and consists of two EMPs aligned in series through a U-tube. The maximum discharge pressure at the designed maximum flow rate is approximately $0.30 \mathrm{MPa}$.

The pressure drop in a piping route from the quench tank to the EMP was calculated by the Darcy-Weisbach formula in a straight pipe. On the other hand, the pressure drop in piping elements such as bends and a valve was calculated by loss coefficients of these elements. As a result, the pressure drop is 24.6 to $25.3 \mathrm{kPa}$ at the design maximum flow rate of $0.05 \mathrm{~m}^{3} / \mathrm{s}$ in the temperature range of 250 to $350{ }^{\circ} \mathrm{C}$.

The static pressure of the Li flow in the annular channel of the EMP is 17.9 to $18.1 \mathrm{kPa}$ in the designed height between the EMP and the quench tank of $9.72 \mathrm{~m}$, and far exceeds the vapor pressure of $\mathrm{Li}$ which are $10^{-3}$ to $10^{-6} \mathrm{~Pa}$ in the above temperature range. The cavitation number is approx. 3 at the max. flow rate of $0.05 \mathrm{~m}^{3} / \mathrm{s}$. As a result, the designed height of $9.72 \mathrm{~m}$ is confirmed to be sufficiently large to prevent cavitation.

\section{REFERENCES}

Garin, P., et al., 2008, Fus. Eng. Des. Vol.83, pp 971-975

Garin, P., et al., 2009, Fus. Eng. Des. Vol.84, pp 259-264

Matsuda, S., 2007, Fus. Eng. Des., Vol.82, pp 435-442

Tsunematsu, T., 2009, Fus. Eng. Des., Vol.84, pp 122-124

Nakamura,H.,et al., 2009, Fus. Eng. Des., Vol.84, pp 252-258

Kondo,H., et al., 2009, Journal of Power and Energy Systems, Vol. 3 , pp. 114-125

Hua, T., 1995, JAERI-Conf-95-019, pp 219

Gol'tsova, E.I., 1966, High Temperature, Vol.4, pp 348

Shpil'rain, E.E.,et al., 1965, HighTemperature, Vol.3, pp 870 
Nesmeyanov, An.N.,et al., 1961, "Vapor pressure of the elements", Academic press

Moody, L. F., 1944, Transactions of A.S.M.E., Vol.66, pp 671

Hammitt, F. G., 1980, Cavitation and Multiphase Flow

Phenomena, Mc Graw-Hill International Book Company

Dell’Orco, G.., 2004, ENEA report, IM-G-R-003 